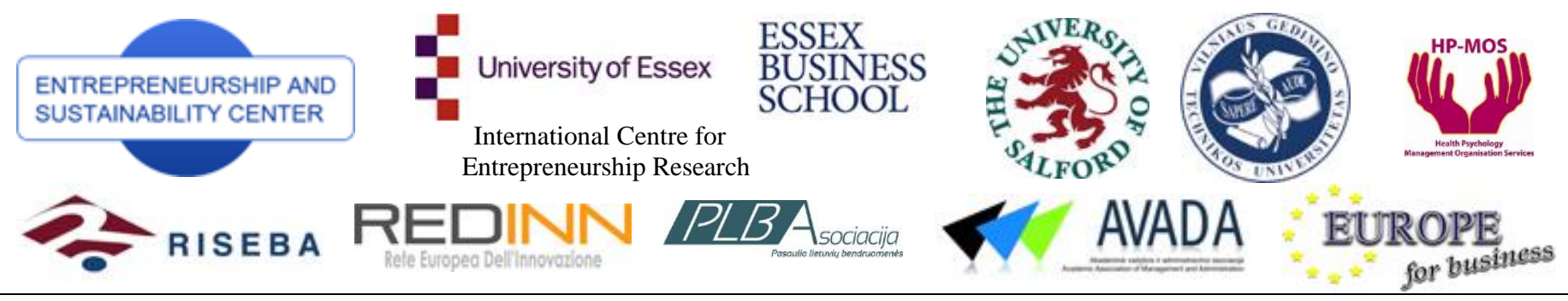

ENTREPRENEURSHIP AND SUSTAINABILITY ISSUES

ISSN 2345-0282 (online) http://jssidoi.org/jesi/

\title{
MANAGEMENT DECISIONS FOR SUSTAINABLE DEVELOPMENT: MEDICAL SOFTWARE CASE STUDY ${ }^{1}$
}

\author{
Laura Baronienè1, Vytautas Žirgutis ${ }^{2}$ \\ ${ }^{1}$ JSC "Softneta", Barsausko str., 59b, Kaunas \\ ${ }^{2}$ Vytautas Magnus University, Economics and Management department. Daukanto str. 28, Kaunas \\ E-mails: ${ }^{1}$ laura.baroniene@softneta.com; ${ }^{2}$.zirgutis@evf.vdu.lt
}

Received 7 November 2016; accepted 6 December 2016

\begin{abstract}
Software is becoming increasingly important and pervasive in healthcare. Deads and injuries, recalls related to the medical software, defective medical device statistics justify the practical dimension of the issue and needs to search ways seeking reduce possibility to arise injuries and deaths. Decision to release medical software to the market is very important not only to the manufacturer (design and development organization), but also for direct and indirect users (doctors and patients) and for all society, which is using national medical system with integrity information technologies possibilities. Manufacturers of medical devices assume responsibility for the correct functioning of medical devices and medical software manufacturer should assume responsibility for medical decisions making and medical decision influence on patient. This responsibility is related not only to the legal and financial risk, but also to the socially responsible business commitments. Software developing companies does not have knowledges about the conditions, which can assure medical software confidence before the release to the market. Such situations stops entrepreneur involvement in the medical software creating area.
\end{abstract}

Keywords: management decisions, medical software reliability, risk evaluation, acceptable risk, innovations

Reference to this paper should be made as follows: 2016. Baronienė, L.; Žirgutis, V.2016. Management decisions for sustainable development: medical software case study, Entrepreneurship and Sustainability Issues 4(2): 129-145.

DOI: http://dx.doi.org/10.9770/jesi.2016.4.2(2)

JEL Classifications: $\mathrm{O} 32$

\section{Introduction}

One of the areas of significant growth in medical devices has been the role of software - as an integral component of a medical device, as a standalone device and more recently as applications on mobile devices. Software is becoming increasingly important and pervasive in healthcare. Given the availability of a multitude of technology platforms (e.g., personal computers, smart phones, network servers, etc.), as well as increasing ease of access and

${ }^{1}$ Research and publication of results was funded by JSC "Softneta" 
distribution (e.g., internet, cloud), software created for medical purposes (software used to make clinical decisions) and non-medical purpose (e.g., administrative, financial) are being used in healthcare.

Manufacturers of medical devices assume responsibility for the correct functioning of medical devices and medical software manufacturer should assume responsibility for medical decisions making and medical decision influence on patient. This responsibility is related not only to the legal and financial risk, but also to the socially responsible business commitments. Decision to release medical software to the market is very important not only to the manufacturer (design and development organization), but also for direct and indirect users (doctors and patients) and for all society, which is using national medical system with integrity information technologies possibilities.

The problem, analyzed in this article, can be formulate as a question "How to manage the risk of business development of medical software creation for IT sector organizations?" Identified problem leads to the goal - to find algorithm, which comply with the legal requirements and would be useful and helpful to the medical software manufacturers.

\section{The main tasks and research results would be following:}

- Describe advanced research scope. This task creates possibility to identify limitations related to the medical software and created management decisions algorithm for sustainable development.

- Describe legal environment in different countries. This task helps to evaluate focus of legal requirements to the medical devices in different countries.

- Formulate of socially responsible solution assumption. This task helps to evaluate, how can be measured benefit of algorithm.

- Describe the adviced algorithm. This task helps to set sequencion and interaction of proposed actions, internal and external risk identification sources, which influence management decision.

- Describe how the algorithm was adopted for the "Softneta" medical device case. This task result must show algorithm adaptation results in user/ patient safety and medical software reliability aspects.

- Describe benefit of biomedical trials. This task results must show justification, why biomedical trials stage is necessary and useful.

Research object. "Softneta" is medical software creating organization. This implies the need to comply with the Lithuanian legal requirements for the medical devices. Case study is applied to the stand-alone medical device: software MedDream WEB DICOM Viewer. Indications for Use: MedDream WEB DICOM Viewer is as software medical imaging system used to receive DICOM images, scheduling information and textual reports, organize and store them in an internal format, and to make that information available across a network via web and customizes user interfaces. Software is intended for use as a diagnostic, review and analysis tool by trained professionals such as radiologists, physicians, clinicians. Contraindications: The MedDream is not intended for the acquisition of mammographic image data and is meant to be used by qualified medical personnel only who are qualified to create and diagnose medical image data.

According to the intended use of the device, MedDream is a stand-alone software that is specifically intended to be used for diagnostic purposes by viewing, archiving and transmitting of medical images. As it is not only suited for archiving or storage of data, it falls within the definition of an active medical device for diagnosis. MEDDEV 2.1/6 Annex $1 \mathrm{c1.4}$ ) links to the Manual on Borderline and Classification in the Community Regulatory Framework for Medical Devices, as it addresses the issue of PACS software systems. MedDream has no postprocessing functions, as well as no control of image acquisition. Also it doesn't drive any other medical device, nor influence the use of a medical image source device, so implementing rule 2.3 "Software, which drives a device or influences the use of a device, falls automatically in the same class." is not applicable and standalone software could be classified in its own right. MedDream allow direct diagnosis from image, also can apply multi- 


\section{The International Journal}

\section{ENTREPRENEURSHIP AND SUSTAINABILITY ISSUES}

ISSN 2345-0282 (online) http://jssidoi.org/jesi/ 2016 Volume 4 Number 2 (December)

planar reconstruction for the better diagnosis. Based on the above mentioned considerations, Rule 10 could be appropriate and MedDream is classified as a Class IIa active medical device.

To ensure safety creation and maintenance medical software, which belongs to the Class IIa medical devices, should be implemented EU requirements for medical software. Medical software distribution in USA conditions requires FDA (Food and Drug Administration) approval/ clearancy, therefore FDA requirements for medical devices also should be implemented and maintained.

Softneta" present their social responsibility by creating rationale management decisions algorithm for sustainable development. This algorithm, created according to the medical devices related legal requirements, standards and good design and development practices, gives answer to the question "when the medical software ensures enough reliability and can be released to the market?" and eliminate restrictions, therefore can be used by other medical software creating organizations.

Methods applied: literature review was used for the article problem justification. Identified problem relevance was approved and legal environment analysis was made by analyzing primary and secondary data sources. Legal requirement analysis results were presented by using benchmarking. "Softneta" case study results were analyzed by using statistical analysis. Conclusion were formulated by using induction and deduction principles.

Literature review. In the US alone, iatrogenic or medical errors are responsible for 100.000 deaths and injuries every year (Kohn, Corrigan, Donaldson, 2000). Dr. Martin Makary claims that medical errors are now the third leading cause of death in the US (Makary M., 2016). The total cost of all medicinal errors in the US has accumulated to approximately 50 billion \$ (Bond, Dewar, Finlay, Nugent, Moore, Guldenring, 2014). European data, mostly from European Union Member States, consistently show that medical errors and health-care related adverse events occur in $8 \%$ to $12 \%$ of hospitalizations. For example, the United Kingdom Department of Health, in its 2000 report An organisation with a memory, estimated about 850000 adverse events a year (10\% of hospital admissions). Spain (in its 2005 national study of adverse events) and France and Denmark have published incidence studies with similar results. Infections associated with health care affect an estimated 1 in 20 hospital patients on average every year (estimated at 4.1 million patients) with the four most common types being: urinary tract infections (27\%), lower respiratory tract infections (24\%), surgical site infections (17\%) and bloodstream infections (10.5\%). Multiresistant Staphylococcus aureus (MRSA) is isolated in about 5\% of all infections associated with health care. The United Kingdom National Audit Office estimates the cost of such infections at $£ 1$ billion per year. While $23 \%$ of European Union citizens claim to have been directly affected by medical error, $18 \%$ claim to have experienced a serious medical error in a hospital and $11 \%$ to have been prescribed wrong medication. Evidence on medical errors shows that $50 \%$ to $70.2 \%$ of such harm can be prevented through comprehensive systematic approaches to patient safety. This statistics, given from World Health Organization regional office for Europe, show that strategies to reduce the rate of adverse events in the European Union alone would lead to the prevention of more than 750000 harm-inflicting medical errors per year, leading in turn to over 3.2 million fewer days of hospitalization, 260000 fewer incidents of permanent disability, and 95000 fewer deaths per year. Above mentioned information creates conditions to think about error prevention. P. Croskerry, D. Sinclair (2001) says that the "science of error prevention" has been deemed a new, yet important topic in medicine. One of the most important causes of medical error can be called as wrong uses of medical devices and/or disfunction of medical devices. It is very important to reduce possible medical devices disfunctions which can lead to patient injury or death. Responsible behavior requires medical software quality and reliability assurance from the developing organizations and helps to ensure social responsibility in hospital governance, which is mentioned as a "new paradigm of hospital governance" (Brandao, Rego, Duarte, Nunes, 2013). Importance of this new parading shows a lot of articles, written by Keyvanara, Sajadi (2015), Liu, Shi, Pong, Chen (2016), Hsieh, Chiu, Hsieh, Ho, Chen, Chang (2016), Iyngkaran, Beneby (2015). Social entrepreneurship, analyzed by Roper, Cheney (2001), Hoogendoorn, Pennings, Thurik (2010), Austin, Stevenson, Wei-Skillern 
(2006), Laspogata, Gail, Cotton, Matya (2003), is one of the biggest challenges for the medical software manufacturers.

Companies that develop, manufacture, and market devices and products used to treat or diagnose disease and injury are facing a growing emphasis on creating ones that provide benefits from a total health economic point of view. This trend, along with slowing growth in developed countries and rapid growth in emerging markets, requires leaders who are market savvy and understand how to drive innovation, reduce costs, and provide improved clinical benefit (Korn Ferry, Medical Devices). "If a medical imaging device malfunctions due to improper servicing, a diagnosis could be missed, care could be delayed, or the patient could be severely injured or even killed" says Patrick Hope (The executive director of the Medical Imaging \& Technology Alliance (MITA), 2016, 7 November) in the article "FDA Must Regulate the Servicing of Medical Imaging Devices to Ensure Patient Safety".

Defective medical device statistics, mentioned below, justify the practical dimension of the issue (data from Rosenfeld: Injury Lawyers ):

- In 2008, there were only 18 high risk medical devices recalled by the FDA.

- This number climbed to 31 the following year and has continued to grow in every subsequent year to date.

- In 2013, 63 high risk devices were recalled by the FDA - which represents an alarming increase of $350 \%$ compared to only five years prior.

- As of August 30, 2014, 42 medical devices have been recalled since the beginning of the year.

- In the period of $2008-2011,45 \%$ of the devices recalled were pulled from the market due to a manufactural defect.

- $\quad 29 \%$ of the recalled devices malfunctioned during use or failed to provide intended results.

- $11 \%$ of the medical devices recalled during this period were found to be contaminated in some way.

- The $510(\mathrm{k})$ program is an approval system that allows the manufacturers of medical devices to bring products to market without first performing clinical trials to ensure product safety and reliability. Manufacturers must only proof that the device is similar to existing devices on the market in order to gain approval through this system.

- $\quad 71 \%$ of high risk devices that have gained approval through the $510(\mathrm{k})$ program were later recalled.

- Revisions have been made to this approval process in 2013 in hopes that stricter standards will reduce the number of harmful products allowed to make it to market.

Software developing companies does not have knowledges about the conditions, which can assure medical software confidence before the release to the market. Even more, no one insurance company in Lithuania does not offer insurance for patient injury cases. Such situations stops entrepreneur involvement in the medical software creating area.

"Softneta" case study analysis scheme for searching rationale management decisions for sustainable development is presented below (Fig.1): 


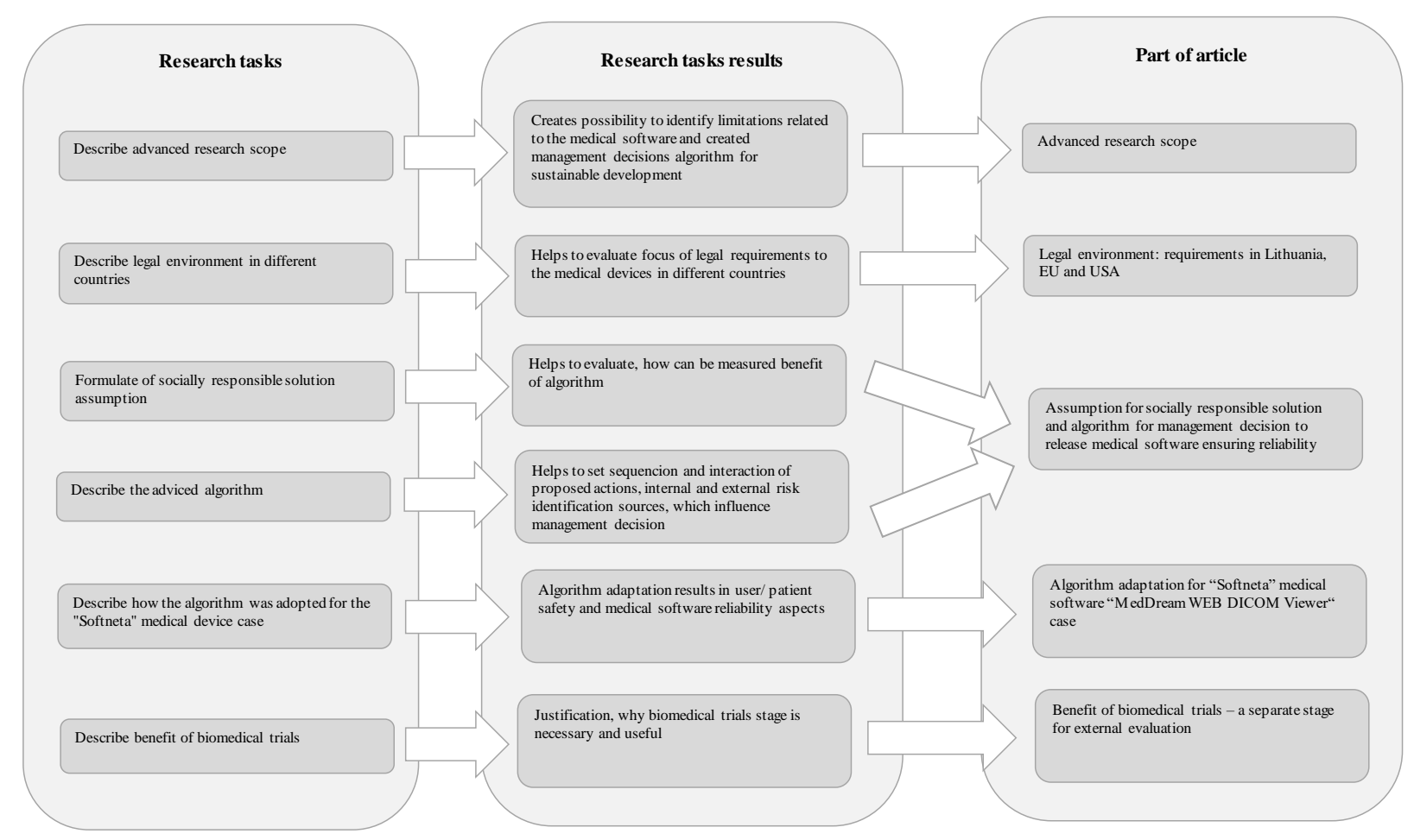

Fig. 1. "Softneta" case study analysis scheme Source: Authors

\section{Advanced research scope}

Advanced research scope gives more detailed information about the medical software:

- Definition and description of device or product, and intended use. MedDream WEB DICOM Viewer is a Flash/HTML based package for PACS server which is designed to aid professionals in everyday's decision making process, connecting all the medical data into a unified and fast performing network. MedDream ensures a fast and reliable way to search, present and analyze the medical data (images and video files) on various devices: computers, smart phones, tablets (near future) and so forth. The system consists of hardware (eg., a network switch, controller) and server / client software (eg., as the final decision) for the transfer of image data from a variety of video / audio and video devices (eg. endoscopic camera, an ultrasound imaging system, radiography digital video system) to standard devices (eg., monitor, personal computer [PC]). Standalone software is considered to be an active medical device, therefore MedDream WEB DICOM Viewer is considered to be an active medical device. MedDream WEB DICOM Viewer was created to use it for medical devices images management. Indications for Use: MedDream is as software medical imaging system used to receive DICOM images, scheduling information and textual reports, organize and store them in an internal format, and to make that information available across a network via web and customizes user interfaces. Software is intended for use as a diagnostic, review and analysis tool by trained professionals such as radiologists, physicians, clinicians. Contraindications: The MedDream is not intended for the acquisition of mammographic image data and is meant to be used by qualified medical personnel only who are qualified to create and diagnose medical image data

- GMDN Code: Medical image management system: A computerized system designed to electronically receive, collect, store, and display a broad range of medical imaging/video data, including patient 


\section{The International Journal}

ENTREPRENEURSHIP AND SUSTAINABILITY ISSUES

ISSN 2345-0282 (online) http://jssidoi.org/jesi/

2016 Volume 4 Number 2 (December)

demographics, and to distribute the data within and between healthcare facilities to facilitate data organization, reporting, and sharing (e.g., teaching). The system consists of combined hardware (e.g., network switch, controller) and server/client software (e.g., as a turnkey solution) intended to relay image data from a broad range of imaging/audiovisual devices (e.g., endoscopic camera, ultrasound imaging system, radiography digital imaging system) to off-the-shelf devices [e.g., monitors, personal computers (PC's)].

- FDA ID Number: 892.2050. Radiology devices: Diagnostic devices: Picture archiving and communications system.

- Category, classification and classification rationale: Classification is carried out according to the requirements of Annex IX of directive 93/42/EEC and guidelines set in MEDDEV 2.4/1 Rev.9. Guidance document MEDDEV 2.1/6 is taken as a reference as it provides guidelines on the qualification and classification of stand-alone software used in healthcare within the regulatory framework of medical devices. According to the intended use of the device, MedDream is a stand-alone software that is specifically intended to be used for diagnostic purposes by viewing, archiving and transmitting of medical images. As it is not only suited for archiving or storage of data, it falls within the definition of an active medical device for diagnosis. MEDDEV 2.1/6 Annex $1 \mathrm{c} 1.4$ ) links to the Manual on Borderline and Classification in the Community Regulatory Framework for Medical Devices, as it addresses the issue of PACS software systems. MedDream has no post-processing functions, as well as no control of image acquisition. Also it doesn't drive any other medical device, nor influence the use of a medical image source device, so implementing rule 2.3 "Software, which drives a device or influences the use of a device, falls automatically in the same class." is not applicable and standalone software could be classified in its own right. MedDream allow direct diagnosis from image, also can apply multi-planar reconstruction for the better diagnosis. Based on the above mentioned considerations, Rule 10 could be appropriate and MedDream is classified as a Class IIa active medical device.

Limitations related to the medical software and created management decisions algorithm for sustainable development are mentioned below. Algorythm is applicable only for medical software, which is/has:

- classified not risky as IIa class.

- recognized as"moderate" managing level.

- $\quad$ no tangible product of expression;

- not required of any material;

- an exception on requirements for sterile medical devices/ this requirement is not applicable. so there is no risk to mix sterile and non-sterile products.

- integrated into the devices, which are not intended to give medication to the patients.

- no components and devices to which software is integrated, can't be treated as pharmaceuticals (also are not intended to give medication to the patients).

\section{Legal environment: requirement in Lithuania, EU and USA}

In general, existing regulations address public health risks of medical software. However, the current application of regulations and controls may not always translate or address the unique public health risks posed by Software as a Medical Device nor assure an appropriate balance between patient/consumer protection and promotion of public health by facilitating innovation (White Paper "Software Development for Medical Devices"). Some regulators have taken individual approaches to assure safety, effectiveness, and performance of Software as a Medical Device. Such approaches have common public health goals. The objective of this effort is to promote consistent expectations for Software as a Medical Device and to provide an optimal level of patient safety while fostering innovation and ensuring patients and providers have continued access to advances in healthcare technology. Medical software fall under regulatory scrutiny. Two prominent regulatory bodies include the FDA 
for medical device products marketed in the U.S., and the European Medical Device Directive for medical device products marketed in the European Union. Lithuania has also very strictly requirements to the medial devices.

The U.S. Code of Federal Regulations (CFR), including 21 CFR Part 11, Electronic Records and Electronic Signatures and 21 CFR Part 820 Quality System (QS) Regulations (as well as ISO 13485 specifications) defines a number of practices and processes which must apply to the development of software that acts as a component of a medical device or is used to aid in the production or manufacturing of a device. The Medical Device Directive (MDD) is a harmonized European standard which protects against the risks associated with the design, manufacturing and packaging of medical devices. Compliance with the requirements of the Medical Devices Directive is declared by placing the CE marking on the product, and supplying the device with a Declaration of Conformity. Conformity requires a series of assessments and examinations of the quality system and examination of the product type and design dossier relating to the product. Lithuania took over the part of the EU requirements, creates additional requirements, especially in field of biomedical research. It is very important to know, that medical software, which is not directly integrated in medical devices (stand-alone medical software), but is treated as "medical device" according to the Medical Device Directive (MDD), should be verified by external users by implementing biomedical trials. In addition to market-specific regulatory requirements such as the FDA 21 CFR 820 and the European Union Medical Device Directive, ISO 13485 provides an overarching ISO standard for quality management systems. Likewise, ISO 14971 focuses on risk management systems, IEC 62366 focuses on usability engineering to medical devices, IEC 62304 focuses on medical device software lifecycle processes. The main legal requirements in different countries are presented in the Table 1.

Table 1. The main legal requirement for medical devices

\begin{tabular}{|c|c|c|}
\hline Lithuania & $\mathbf{E U}$ & USA \\
\hline $\begin{array}{lr}\text { 1. } & \begin{array}{l}\text { Lithuanian medical } \\
\text { norm MN } 4: 2009 \\
\text { "Technical } \\
\text { Regulation } \\
\text { Medical on } \\
\text { Safety" }\end{array} \\
\text { 2. } & \begin{array}{l}\text { Biomedical } \\
\text { Research Ethics }\end{array} \\
\text { Law } & \\
\text { 3. } & \begin{array}{l}\text { Procedure of the } \\
\text { medical device } \\
\text { installation, use and } \\
\text { maintenance }\end{array}\end{array}$ & 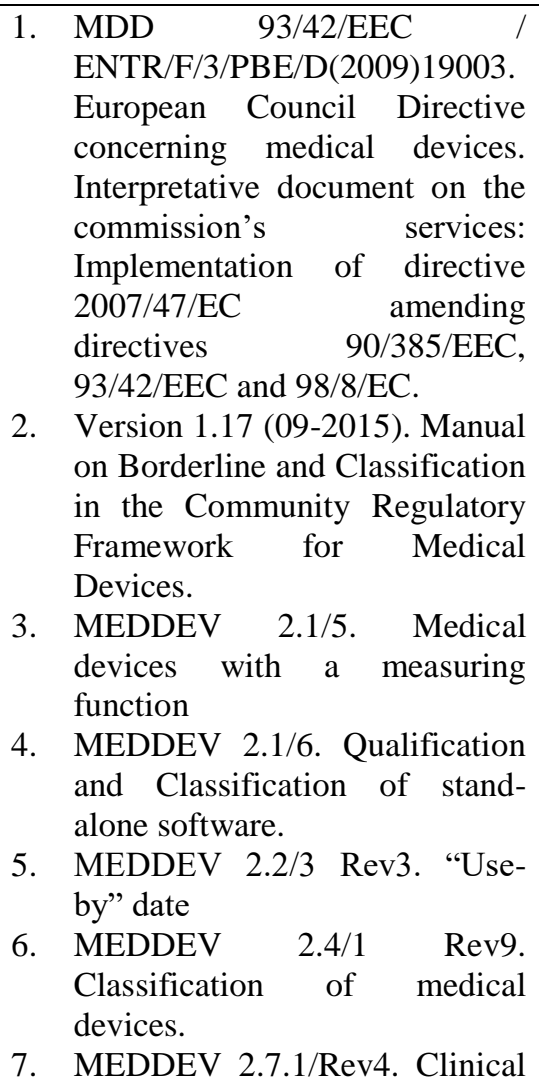 & $\begin{array}{l}\text { 1. U.S. FDA Medical Device } \\
\text { Regulation: } 21 \text { C.F.R. Part } 820 \\
\text { (Quality System regulation). } \\
\text { 2. U.S. FDA Medical Device } \\
\text { Regulation: } 21 \text { C.F.R. Part } 801 \text { et } \\
\text { seq. (Labeling) } \\
\text { 3. U.S. FDA MAF Regulation: } 21 \\
\text { C.F.R. section 814.9. (Medical } \\
\text { Device Master File) } \\
\text { 4. U.S. FDA 510(k) Regulation: } 21 \\
\text { C.F.R. section 814.9. (Premarket } \\
\text { approval of medical devices) } \\
\text { 5. Overview of Regulatory } \\
\text { Requirements: Medical Devices } \\
\text { 6. Software related documentation } \\
\text { 7. General Principles of Software } \\
\text { Validation; Final Guidance for } \\
\text { Industry and FDA Staff } \\
\text { 8. FDA guidelines to User Manual }\end{array}$ \\
\hline
\end{tabular}




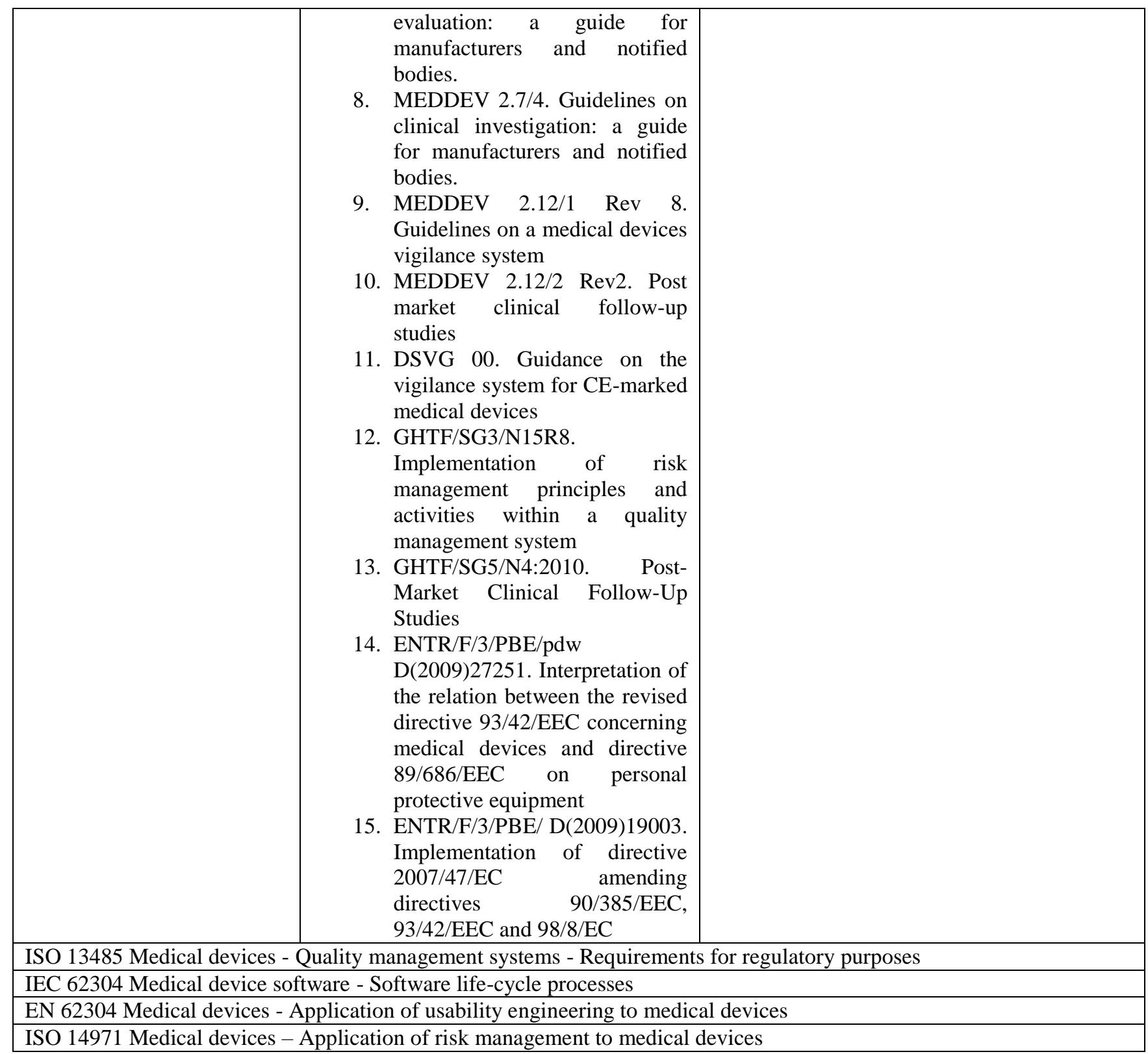

Source: Authors

Lithuanian legal requirements highlights reliability based on biomedical researches, EU legal requirements highlights reliability based on risk management and clinical evaluation and USA legal requirements highlights reliability based on internal verification and validation, risk management. White Paper "Software Development for Medical Devices" reviews some of the key challenges facing the medical device industry. One of the mentioned challenges is "managing risk and reducing recalls". Global software development solutions (simplified electronic tracking of requirements, risks and mitigations with relationships and dependencies; automatically compute Risk Priority Number (RPN); automated support for V-Model with named relationships between requirements, design, and software assets and their associated verification and validation assets) creates benefits: reduced risk, improving productivity while maintaining compliance and managing risk (White Paper "Software 
Development for Medical Devices"). Not enough rationale management decisions to release medical software leads to recalls.

Stericycle ExpertSOLUTIONS track the latest recall trends across industries. Since 2012, 783,000 medical devices have been recalled due to software issues across 280 events. Not only has new technology caused an increase in recalls, these recalls have become much more complex. Based on the Stericycle ExpertSOLUTIONS Q3 Index Report, 28 percent of medical device companies experienced more than one recall, and one company had 23 recalls during the third quarter of 2015 alone (data from Swiss Agency for Therapeutic Products. Medical devices - List of recalls and other field safety corrective actions (FSCA)).

Swiss Agency for Therapeutic Products published list of recalls and other field safety corrective actions (FSCA) from 2016 year. 2 of 57 cases is related with medical software:

- Telemis-Medical Software Version: 4.60, 4.70. MD: Picture archiving and communication system. Problem description: In some rare circumstances, there could be a difference between measure value displayed in the viewer and the one stored internally (the stored value is visible in the measure manager window (Urgent - Field Safety Notice Telemis-Medical Software FSCA 20369).

- CONTOUR DIABETES App Software Version: 1.0.5 and lower. MD: Data management system, patient. Problem description: In very rare cases, some of the data stored in the CONTOUR CLOUD could be incomplete (Urgent fiels safety notice „Conour TM Diabetes APP and Contour Cloud Synchronization Customer Email“).

\section{Assumption for socially responsible solution and algorithm for management decision to release medical software ensuring reliability}

Decision to release medical software should be made when manufacturer can assure reliability. Reliability can be translated in to the measuring units and could have mathematical expression, further mentioned as risk/benefit calculation, as shown below:

$$
\text { Result }=\left(\frac{w e}{\text { ole*ro*cos }}\right) * 100 \% \text {, where }
$$

uc - user count (further medical software version user count or planned medical software user count)

clc - count of code lines (programinès įrangos eilučiu skaičius)

$\mathrm{rc}-$ count of risks (total count of residual risks)

$\cos -$ coeficien), which is classified according to the overall residual risk estimate.

If the risk/benefit value (in percent) is less than 1 (one), considered that the software benefits outweigh the risks that may be encountered while using the software. If the software utility is equal to the risk (the risk-benefit ratio as a percentage value is equal to 1 (one) or less than the potential risks (that is greater than 1), then the version of the software can't be released to the market.

Clinical evaluation (as presented it the Figure 2), lasting during the whole design and development process, helps to identify critical issues for potential risk. 
The International Journal

ENTREPRENEURSHIP AND SUSTAINABILITY ISSUES

ISSN 2345-0282 (online) http://jssidoi.org/jesi/

2016 Volume 4 Number 2 (December)

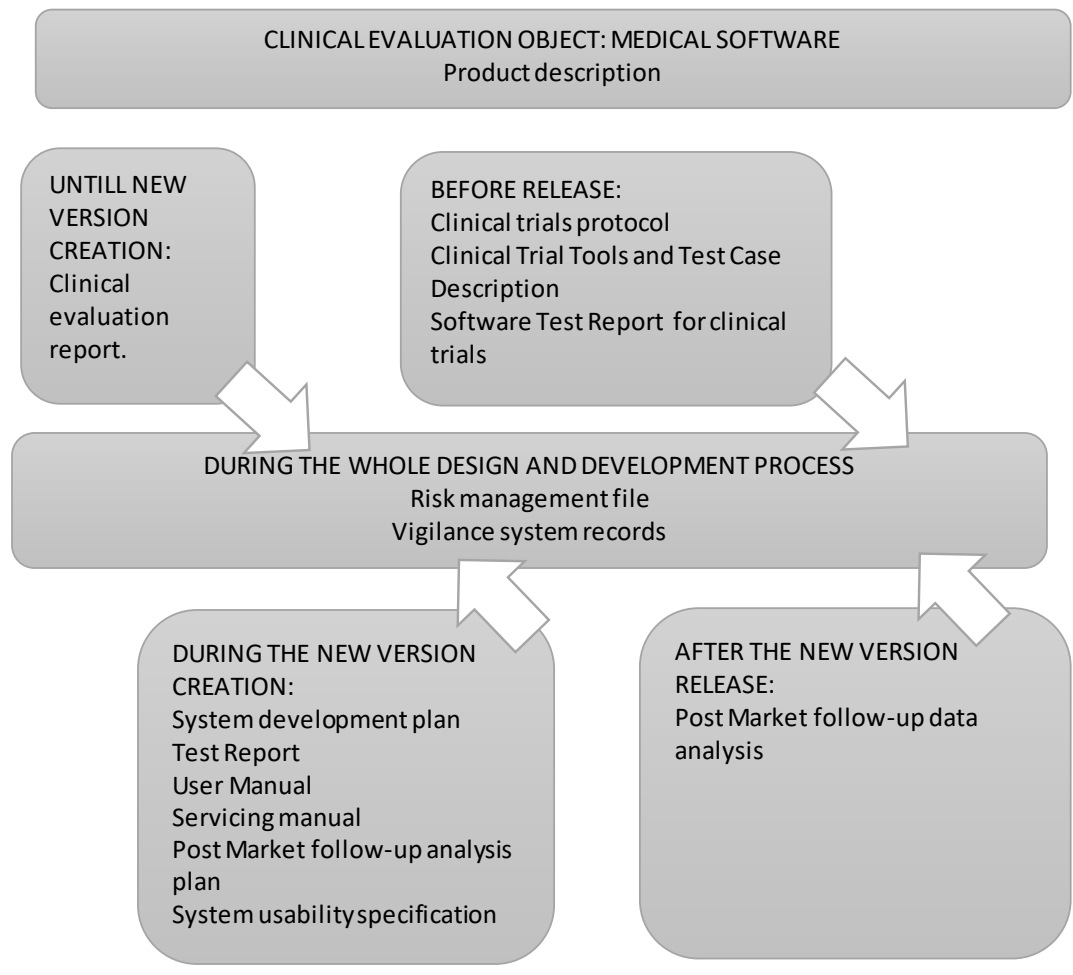

Fig 2. Clinical evaluation during the whole design and development process Source: Authors

This picture presents internal and external data sources, which can help to identify the new potential risk (or eliminate/ reduce risk occurrence probability). Each new risk (or new risk source) should be estimated according to the initial risk evaluating method. Below presented algorithm (picture 3) shows the main stages, where risk can be identified. To ensure medical software reliability no one of the stages can be missed. 


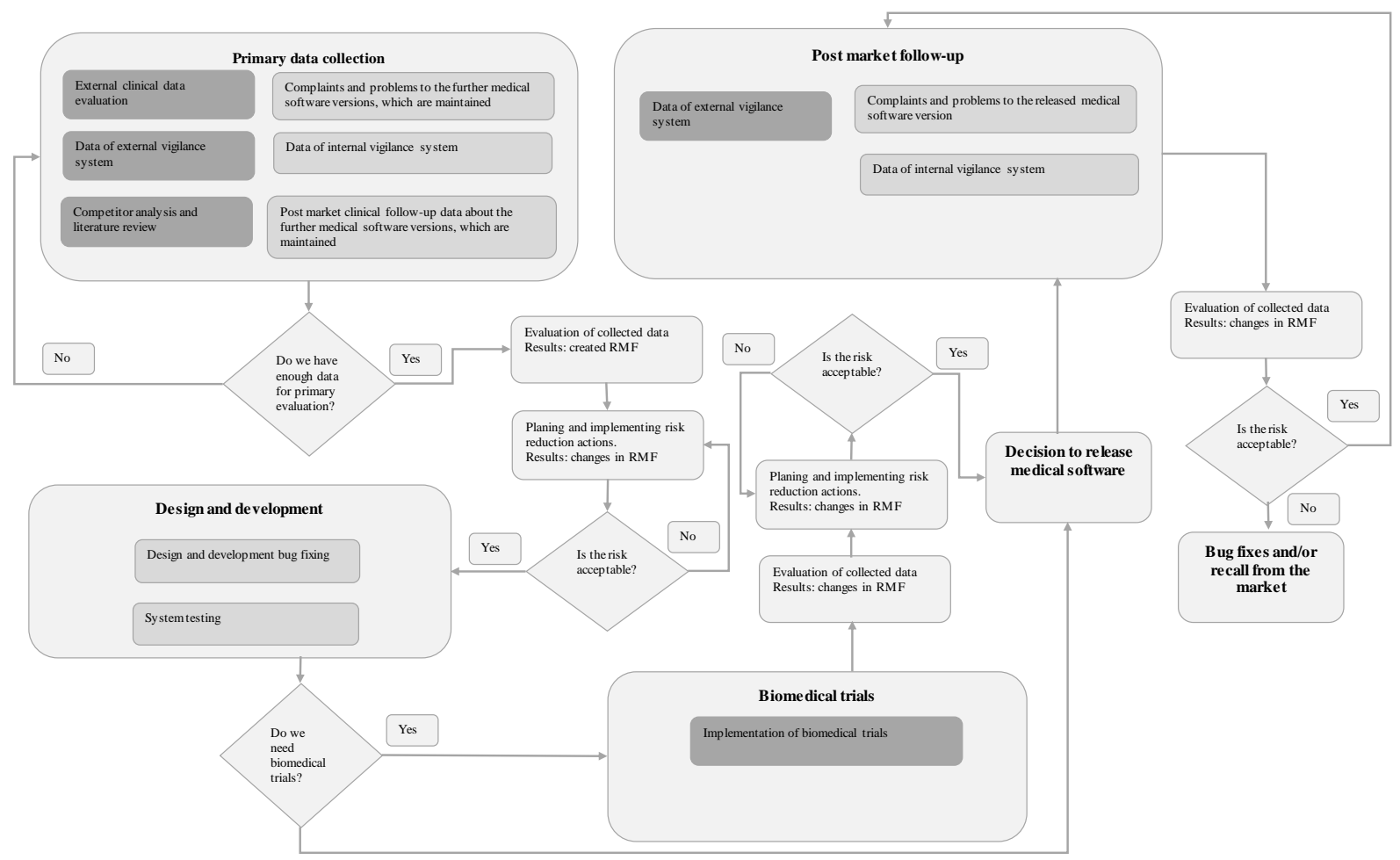

Fig 3. Algorithm for management decision to release medical software ensuring reliability Source: Authors

Abowe (in Figure 3) it is presented algorithm used by "Softneta" aiming to ensure the possible lowest residual risk results.

\section{Algorithm adaptation for "Softneta" medical software "MedDream WEB DICOM Viewer" case}

Risk assessment results, based on real "Softneta" medical software data, presented in the table below (Table 2). 
Table 2. "Softneta" medical software risk assessment results

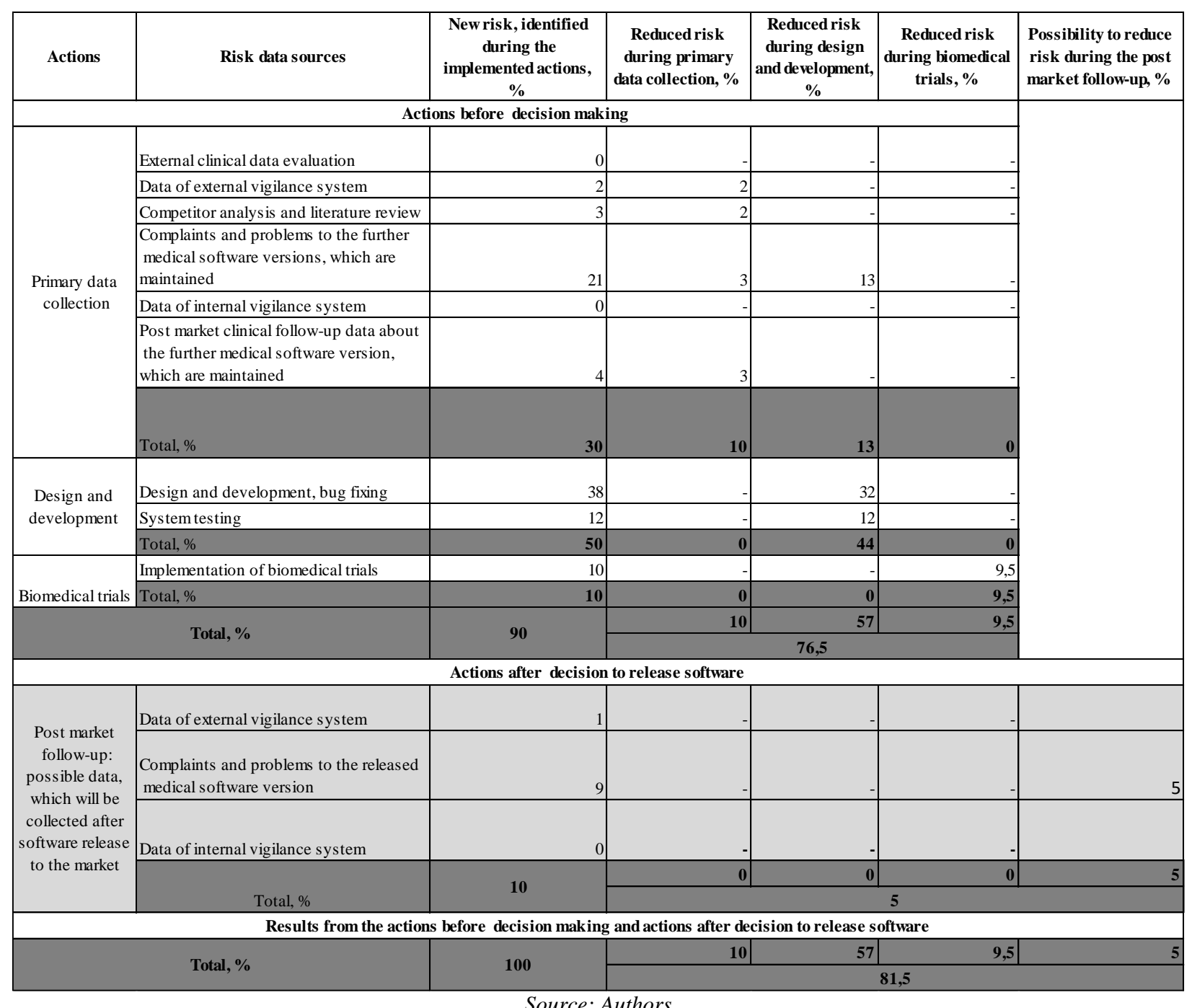

As shown in the table 2, decision to release medical software to the market should be made before post market follow-up. It means, that possible risks may arise after the release. Implemented actions before the decision to release medical software to the market ensure low possibility to identify many risks during the post market follow-up period. Previous „Softneta“ case studies shows, that new arised risk is not exceed 7 percent. In this case study foreseen 3 percent inaccuracy leads to the 10 percent possible risk, identified during the post market follow-up period. Case study results shows, that decision to release medical software to the market were made when 76,5 percent risk (from the 90 percent identified risk) (or 85 percent from 100 percent identified risk (if all risk, identified during the actions before decision making, equals 100 percent)) cases were solved. Not eliminated risk is treated as known bugs and would be given to the users as a part of IFU (Instructions for users).

Calculated risk/benefit results by release the medical software were 0,00002 . It means, that the software benefits outweigh the risks that may be encountered while using the software. This result shows probability to arise 
problem/complain in 2 of 100000 cases (or 1 of 50000 cases). Risk, related to software functions, which can lead to injury, were eliminated. According to the algorithm, the new risk (10 percent) can arise during the post market follow-up period. If the new risk would be identified, the worst risk/benefit result can reduce risk/benefit results 10 percent. In such case risk/benefit results would be 0,000022 (probability to arise problem/complain in 22 of 1000000 cases ( 1 of 45455 cases). In "Softneta" case this result assure reliability of the medical software (number of users does not exceed 100 000). Other organizations, working according to the presented algorithm, should interpret results in their context and have justification for the made decision to release medical software to the market. One inexperienced injury can be evaluated using the data from insurance policy: 1000000 EUR for each and every claim, including cost and expenses. The Table 3, presented below, shows the benefits of applying the algorithm.

Table 3. Benefits of applying the algorithm

\begin{tabular}{|c|c|c|c|c|c|c|c|}
\hline $\begin{array}{l}\text { Algorithm } \\
\text { actions }\end{array}$ & $\begin{array}{c}\text { New risk, } \\
\text { identified } \\
\text { during the } \\
\text { implemented } \\
\text { actions, \% }\end{array}$ & $\begin{array}{c}\text { Reduced } \\
\text { risk } \\
\text { during } \\
\text { primary } \\
\text { data } \\
\text { collection, } \\
\%\end{array}$ & $\begin{array}{c}\text { Reduced risk } \\
\text { during design } \\
\text { and } \\
\text { development, } \\
\%\end{array}$ & $\begin{array}{c}\text { Reduced } \\
\text { risk } \\
\text { during } \\
\text { biomedical } \\
\text { trials, \% }\end{array}$ & $\begin{array}{c}\text { Possibility } \\
\text { to reduce } \\
\text { risk during } \\
\text { the post } \\
\text { market } \\
\text { follow-up, } \\
\%\end{array}$ & $\begin{array}{c}\text { Probability to } \\
\text { arise } \\
\text { problems/injury } \\
\text { before the } \\
\text { implemented } \\
\text { actions }\end{array}$ & $\begin{array}{c}\text { Probability to } \\
\text { arise } \\
\text { problems/injury } \\
\text { after the } \\
\text { implemented } \\
\text { actions }\end{array}$ \\
\hline $\begin{array}{l}\text { Primary data } \\
\text { collection }\end{array}$ & 30 & 10 & 13 & 0 & & $\mathrm{x}$ & $\mathrm{x}$ \\
\hline $\begin{array}{l}\text { Design and } \\
\text { development }\end{array}$ & 50 & 0 & 44 & 0 & & 1 of 30303 cases & 1 of 45455 cases \\
\hline $\begin{array}{l}\text { Biomedical } \\
\text { trials }\end{array}$ & 10 & 0 & 0 & 9,5 & & 1 of 45455 cases & 1 of 50000 cases \\
\hline $\begin{array}{l}\text { Post market } \\
\text { follow-up }\end{array}$ & 10 & 0 & 0 & 0 & 5 & 1 of 50000 cases & 1 of 49751 cases \\
\hline
\end{tabular}

Risk/benefit score can be calculated having primary information not only about risk, but also about the count of code lines. This data can be firstly used in stage of design and development. Each algorithm action helps to reduce probability to arise problems/injury and shows possible result if any actions could be not implemented.

\section{Benefit of biomedical trials - a separate stage for external evaluation}

In order to know biomedical trials impact to the management decision to release medical software to the market, the biomedical trials were implemented. Data, presented in table No. 3, were obtained by in cooperation with Vilnius Santariskes clinics during the biomedical research for Medical Software product Meddream Web DICOM Viewer. The sample size was determined according to the respondent calculator which was made on the basis of T. Yamane, V.A Jadov and research organization "Factus" experience. The sample size (Table 4) is presented below. 
Table 4. The sample size for biomedical trials

\begin{tabular}{|l|l|l|l|l|l|}
\hline $\begin{array}{l}\text { Investigation per } \\
\text { year, units: X-rays }\end{array}$ & 50.000 & $\begin{array}{l}\text { Investigation per year, } \\
\text { units: KT }\end{array}$ & 30.000 & $\begin{array}{l}\text { Investigation per year, } \\
\text { units: MRT }\end{array}$ & 5.000 \\
\hline Probability, \% & 95 & Probability, \% & 95 & Probability, \% \\
\hline Inaccuracy, \% & 10 & Inaccuracy, \% & 10 & Inaccuracy, \% & S5 \\
\hline Sample size, units & 96 & Sample size, units & 96 & Sample size, units \\
\hline $\begin{array}{l}\text { Total sample size, } \\
\text { units }\end{array}$ & 286 & \multicolumn{3}{|c|}{ Source: Authors } \\
\hline
\end{tabular}

This biomedical evaluation were implemented for Medical Software product Meddream Web DICOM Viewer for the purpose to ensure maximum patient safety using this software. The main tasks of biomedical evaluation:

- To verify that the fully integrated and final system to be delivered meets the specification and its purpose;

- To get a confirmation from the user that system is accepted and solves those business problems for whitch it was designed to automate;

- Performance: if Meddream Viewer achieves the performances intended by Softneta UAB;

- Safety: if undesirable side-effects, under normal conditions of use, are acceptable when weighed against the benefits to the patient.

- To determine any undesirable side effects and to make sure that the side effects by normal usage environment are acceptable risks (weighed against the intended operation of the medical device).

Data, presented in table 4, leads to thinking, that biomedical trials is very important actions, which can essure better reliability of medical software.

\section{Conclusions}

Manufacturers of medical devices assume responsibility for the correct functioning of medical devices and medical software manufacturer should assume responsibility for medical decisions making and medical decision influence on patient. This responsibility is related not only to the legal and financial risk, but also to the socially responsible business commitments.

Software developing companies does not have knowledges about the conditions, which can assure medical software confidence before the release to the market. Even more, no one insurance company in Lithuania does not offer insurance for patient injury cases. Such situations stops entrepreneur involvement in the medical software creating area.

"Softneta" present their social responsibility by creating rationale management decisions algorithm for sustainable development. This algorithm, created according to the medical devices related legal requirements, standards and good design and development practices, gives answer to the question "when the medical software ensures enough reliability and can be released to the market?" and eliminate restrictions, therefore can be used by other medical software creating organizations.

The current application of regulations and controls may not always translate or address the unique public health risks posed by Software as a Medical Device nor assure an appropriate balance between patient/consumer protection and promotion of public health by facilitating innovation.

Case study is applied to the stand-alone medical device: software MedDream WEB DICOM Viewer, which is classified as a Class IIa active medical device and for the safety creation and maintenance conditions, also for the selling conditions should comply Lithuanian, EU and USA (FDA) legal requirements. 
Lithuanian legal requirements highlights reliability based on biomedical researches, EU legal requirements highlights reliability based on risk management and clinical evaluation and USA legal requirements highlights reliability based on internal verification and validation, risk management. All this approach are integrated by creating algorithm for management decisions for sustainable development (for the decision to release medical software to the market).

Algorythm is applicable only for medical software, which is/has classified not risky as IIa class; recognized as"moderate" managing level; no tangible product of expression; not required of any material; an exception on requirements for sterile medical devices/ this requirement is not applicable. so there is no risk to mix sterile and non-sterile products; integrated into the devices, which are not intended to give medication to the patients; no components and devices to which software is integrated, can't be treated as pharmaceuticals (also are not intended to give medication to the patients).

Decision to release medical software should be made when manufacturer can assure reliability. Reliability can be translated in to the measuring units and could have mathematical expression, which advices authors.

Medical software reliability depends on risk management results, using clinical evaluation data during the whole design and development process.

Algorithm for management decision to release medical software ensuring reliability were used by "Softneta" in order to ensure the possible lowest residual risk results.

Case study results shows, that decision to release medical software to the market were made when 76,5 percent risk (from the 90 percent identified risk) (or 85 percent from 100 percent identified risk (if all risk, identified during the actions before decision making, equals 100 percent)) cases were solved. Not eliminated risk is treated as known bugs and would be given to the users as a part of IFU (Instructions for users).

Calculated risk/benefit results by release the medical software were 0,00002. It means, that the software benefits outweigh the risks that may be encountered while using the software. This result shows probability to arise problem/complain in 2 of 100000 cases (or 1 of 50000 cases). Risk, related to software functions, which can lead to injury, were eliminated.

According to the algorithm, the new risk (10 percent) can arise during the post market follow-up period. If the new risk would be identified, the worst risk/benefit result can reduce risk/benefit results 10 percent. In such case risk/benefit results would be 0,000022 (probability to arise problem/complain in 22 of 1000000 cases (1 of 45455 cases).

By the calculating probability to arise problems/injury before and afer the implemented actions algorithm action helps to reduce probability to arise problems/injury and shows possible result if any actions could be not implemented.

Biomedical trials - a separate stage for external evaluation shows that biomedical trials were very important seeking to essure better reliability of medical software (reduced probability to arise problems/injury from 1 of 45455 cases till 1 of 50000 cases.

Financial benefit of biomedical trials can be calculated using data from insurance policy: 1000000 EUR for each and every claim, including cost and expenses. 
To ensure case studies results extension for the summarized calculation about each algorithm implementation stage, the case study schould be replicated to the other medical software creating organizations.

\section{Acknoledgements}

Research and publication of results was funded by JSC "Softneta"

\section{References}

Austin, J., Stevenson, H., Wei-Skillern, J. Social and Commercial Entrepreneurship: Same, Different, or Both? Entrepreneurship theory and practice. Volume 30, Issue 1, January 2006, pages 1-22.

Bond, R. R., Finlay, D. D., Nugent, Ch, D., Moore, G., Guldenring, D. A usability evaluation of medical software at an expert conference setting. Computer methods and programs in biomedicine 113 (2014) 383-395.

Brandao, Ch., Rego, G., Duarte, I. and Nunes, R. Social Responsibility“ A New Paradigm of Hospital Governance. Health Care Anal. 2013; 21(4): 390-402. Published online 2012 Apr 6. doi: 10.1007/s10728-012-0206-3.

Croskerry, P., Sinclair, D. Emergency medicine: a practice prone to error,Can J. Emerg. Med 3 (2001) 271-276.

Hoogendoorn, B., Pennings, E., Thurik, R. What Do We Know About Social Entrepreneurship: An Analysis of Empirical Research. (January 2010 6,). ERIM Report Series Reference No. ERS-2009-044-ORG. Available at SSRN: https://ssrn.com/abstract=1462018.

Hsieh, SC, Chiu, HC, Hsieh, YH, Ho, PS, Chen, LC, Chang, WC. The Perceptions and Expectations Toward the Social Responsibility of Hospitals and Organizational Commitment of Nursing Staff. J Nurs Res. 2016 Sep;24(3):249-61. doi: 10.1097/jnr.0000000000000133.

Iyngkaran, P., Beneby, G. S. Toward phase 4 trials in hearth failure: A social and corporate responsibility of the medical profession. World J. Methodol. 2015 Dec 26; 5(4): 179-184. Published online 2015 Dec 26. doi: 10.5662/wjm.v5.i4.179.

Keyvanara, M., Sajadi, HS. Social responsibility of the hospitals in Isfahn city, Iran: Results from a cross-sectional survey. Int J. Health Policy Management. 2015 Feb 12;4(8):517-22. doi: 10.15171/ijhpm.2015.29.

Kohn, L. T. Corrigan, J., Donaldson, M. S.To Err is Human: Building a Safer Health System, 1st ed., National Academies Press, Washington, DC, 2000.

Laspogata, Gail A., Cotton, Matya N. Contemplatin "Enterprise": the business and legal challenges of social entrepreneurship. American Business Law Journal 41.1 (Fall 2003): 67-113. Available on the Internet <http://www.kornferry.com/expertise/life-sciences/medicaldevices>.

Liu W., Shi, L., Pong, R. W., Chen, Y. How patients think about social responsibility of public hospitals in China? BMC Health Serv Res. 2016; 16: 371. Published online 2016 Aug 11. doi: 10.1186/s12913-016-1621-1.

Makaray, M. Medical error - the third leading cause of death in the US. BMJ 2016; 353 doi: (Published 03 May 2016). Available on the Internet < http://dx.doi.org/10.1136/bmj.i2139>.

Pollack, K. Why a Medical Device Software Glitch Doesn't Mean a Recall Failure. Available on the Internet https://www.mdtmag.com/blog/2016/02/why-medical-device-software-glitch-doesnt-mean-recall-failure.

Roper, J., Cheney, G. The meanings of social entrepreneurship today. Corporate Governance: The international journal of business in society,online from 2001. Available on the Internet < http://www.emeraldinsight.com/doi/full/10.1108/14720700510604733>.

Rosenfeld: Injury Lawyers. Statistics on Medical Device Recalls. Available on the Internet <https://www.rosenfeldinjurylawyers.com/statistics-on-medical-device-recalls.html http://www.imdrf.org/docs/imdrf/final/technical/imdrf-tech-131209-samd-key-definitions-140901.pdf>. 
The International Journal

ENTREPRENEURSHIP AND SUSTAINABILITY ISSUES

ISSN 2345-0282 (online) http://jssidoi.org/jesi/ 2016 Volume 4 Number 2 (December)

Ascensia. Urgent fiels safety notice „Conour TM Diabetes APP and Contour Cloud Synchronization Customer Email“ Available on the Internet $<$ https://www.swissmedic.ch/recalllists_dl/14539/Vk_20161017_04_e1.pdf $>$.

Medical Device and Diagnostic Industry. Available on the Internet http://www.mddionline.com/blog/devicetalk/fda-must-regulateservicing-medical-imaging-devices-ensure-patient-safety-11-07-16

Swiss Agency for Therapeutic Products. Medical devices - List of recalls and other field safety corrective actions (FSCA). Available on the Internet 〈https://www.swissmedic.ch/rueckrufe_medizinprodukte/index.html?lang=en>.

Telemis. Urgent - Field Safety Notice Telemis-Medical Software FSCA 20369. Available on the Internet <https://www.swissmedic.ch/recalllists_dl/14572/Vk_20161019_05_e1.pdf $>$.

White Paper "Software Development for Medical Devices". Available on the Internet http://www.ptc.com/File\%20Library/Product\%20Families/Integrity/Shared\%20Items/Software Development for Medical Devices.p

World Health Organization regional office for Europe. Available on the Internet <http://www.euro.who.int/en/health-topics/Healthsystems/patient-safety/data-and-statistics>.

Laura Baronienè, Master's degree in management at Kaunas Technology University, Economics and Management department. She is currently working as a quality manager in "Softneta" and is responsible for ensuring compliance to the Lithuanian, EU and USA (FDA) requirements for medical devices. Her research areas are quality management, management decisions, innovation management, medical device quality management.

ORCID ID: orcid.org/0000-0002-1989-8688

Researcher ID: R-2836-2016

Vytautas Žirgutis, Phd is lecturer at Vytautas Magnus University, Economics and Management department. His research areas are strategic management, quality management and stakeholders' management.

ORCID ID: orcid.org/0000-0003-1893-1113

Researcher ID: R-3706-2016

Copyright (C) 2016 by author(s) and VsI Entrepreneurship and Sustainability Center This work is licensed under the Creative Commons Attribution International License (CC BY). http://creativecommons.org/licenses/by/4.0/

(c) (i) Open Access 